\title{
Atypical Skin Rash in Seronegative Secondary Syphilis
}

\author{
Masanori Furuhata, Naoki Yanagisawa and Akihiko Suganuma
}

Key words: HIV, skin rash, seronegative secondary syphilis

(Intern Med 55: 3547, 2016)

(DOI: 10.2169/internalmedicine.55.7288)

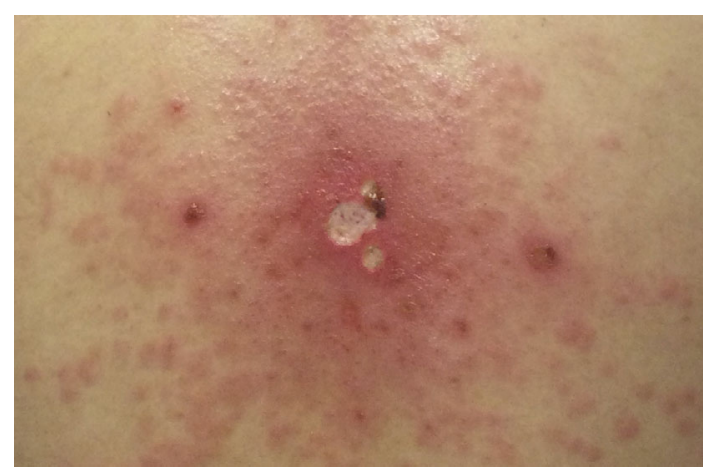

Picture 1.

A 26-year-old HIV-infected man presented with fever and disseminated maculopapular rash not involving his palms and soles. He had started antiretroviral therapy (ART) with an abacavir-based regimen three days prior. Although he tested negative for HLA-B*5701, the antiretrovirals were suspected to be the offending agent associated with the drug eruption. Within several days after discontinuing the ART, his clinical symptoms resided, but a skin rash accompanied by a small ulcer remained on his back (Picture 1). Skin biopsy demonstrated lymphocyte infiltration into the dermis on hematoxylin and eosin staining and Treponema pallidum on immunohistochemical staining (Picture 2). His syphilis serological titer was negative, and a prozone phenomenon was excluded. Based on the pathological evidence, penicillin was initiated, leading to a dramatic clinical response. Two months later, his Treponema pallidum Latex Agglutination test seroconverted. Physicians need to be aware of the possibility of seronegative secondary syphilis, especially in HIVinfected patients, and skin biopsy should be conducted for refractory skin lesions (1). In addition, a polymerase chain reaction test with sufficient sensitivity and specificity may facilitate the diagnosis of syphilis (2).

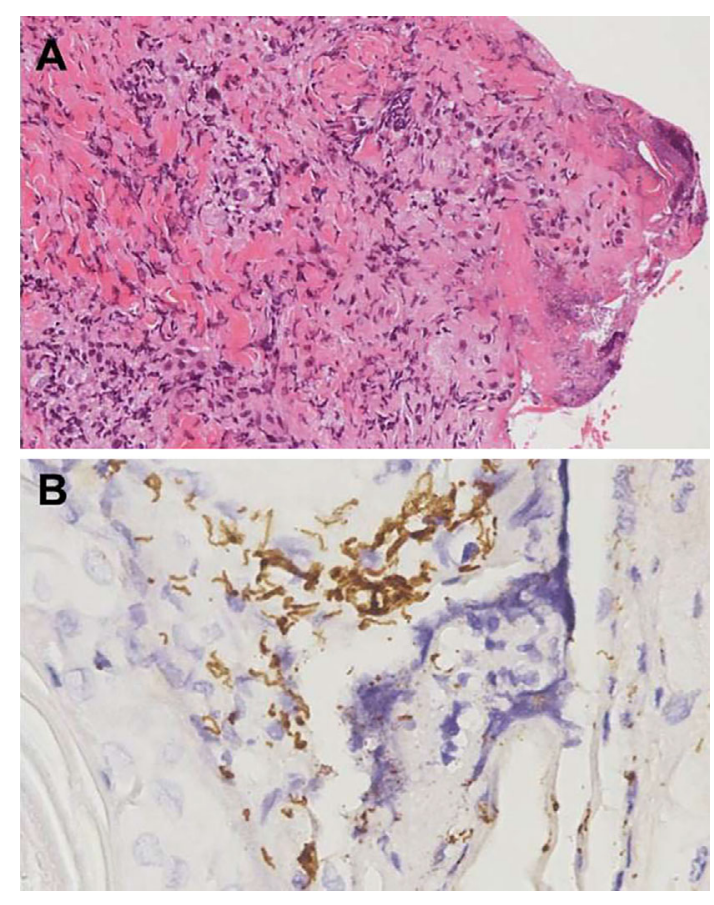

Picture 2.

The authors state that they have no Conflict of Interest (COI).

\section{References}

1. Kingston AA, Vujevich J, Shapiro M, et al. Seronegative secondary syphilis in 2 patients coinfected with human immunodeficiency virus. Arch Dermatol 141: 431-433, 2005.

2. Buffet M, Grange PA, Gerhardt P, et al. Diagnosing Treponema pallidum in secondary syphilis by PCR and immunohistochemistry. J Invest Dermatol 127: 2345-2350, 2007.

The Internal Medicine is an Open Access article distributed under the Creative Commons Attribution-NonCommercial-NoDerivatives 4.0 International License. To view the details of this license, please visit (https://creativecommons.org/licenses/ by-nc-nd/4.0/).

Department of Infectious Diseases, Tokyo Metropolitan Komagome Hospital, Japan

Received for publication February 17, 2016; Accepted for publication April 19, 2016

Correspondence to Dr. Naoki Yanagisawa, naokiy-97@umin.ac.jp

(C) 2016 The Japanese Society of Internal Medicine Journal Website: http://www.naika.or.jp/imonline/index.html 